\title{
Effect of task-oriented exercise training program on the functional performance of children with cerebral palsy
}

\author{
DOI: https://doi.org/10.5114/pq.2020.100293
}

\author{
Umaru Muhammad Badaru', Omoyemi Olubunmi Ogwumike², Ade Fatai Adeniyi ${ }^{2}$ \\ ${ }^{1}$ Department of Physiotherapy, Faculty of Allied Health Sciences, Bayero University, Kano, Nigeria \\ ${ }^{2}$ Department of Physiotherapy, College of Medicine, University of Ibadan, Ibadan, Nigeria
}

\section{Abstract}

Introduction. To evaluate the effects of task-oriented exercise training program (TOET) on the functional performance (mobility and walking efficiency) of children with cerebral palsy (CP).

Methods. Overall, 46 children with CP were recruited from outpatient units of the physiotherapy clinics of Aminu Kano Teaching Hospital, Murtala Mohammed Specialist Hospital, and a school for children with disabilities. They were randomly assigned to the TOET group $(n=23)$ and the control group (CG) $(n=23)$. Children in CG practised conventional physiotherapy. Each group trained twice weekly for 12 weeks. Mobility and walking efficiency were assessed with a mobility questionnaire and 10-meter walk test, respectively, at baseline, after 6th and 12th weeks, and after 6 weeks of follow-up. Data were analysed with repeated measures ANOVA, $t$-test, Mann-Whitney $\mathrm{U}$ test, and Friedman's test, with $\alpha<0.05$.

Results. A total of 39 children with CP completed the study, 19 in CG and 20 in TOET group. The between-group scores of mobility (TOET: $69.15 \pm$ 17.32; CG: $67.03 \pm 10.49$ ) and walking efficiency (TOET: $0.63 \pm 0.2 \mathrm{~m} / \mathrm{s}$; CG: $0.63 \pm 0.19 \mathrm{~m} / \mathrm{s}$ ) were not different at baseline and at the $6^{\text {th }}$ week $(p>0.05)$. At the $12^{\text {th }}$ week, there were significant between-group differences in mobility (TOET: $86.16 \pm 7.20$; CG: $71.09 \pm 13.58$ ) and walking efficiency (TOET: $1.00 \pm 0.29 \mathrm{~m} / \mathrm{s}$; CG: $0.78 \pm 0.28 \mathrm{~m} / \mathrm{s})(p<0.05)$. The within-group scores of walking efficiency and mobility increased in both TOET and CG ( $p<0.005$ for both comparisons).

Conclusions. TOET is an effective intervention to improve functional performance of children with CP.

Key words: mobility, task-oriented exercise training, cerebral palsy, functional performance, walking efficiency

\section{Introduction}

Cerebral palsy $(\mathrm{CP})$ is often associated with poor functional performance, that is, impairments of mobility [1, 2] and walking efficiency $[3,4]$. The task-oriented exercise training program (TOET) is a potential neurological rehabilitation technique for the enhancement of the functional performance in children with CP [5-8]. This contemporary technique of neurological rehabilitation involved the use of 'functional strengthening, balance training, aerobic exercise, and the practice of a variety of walking tasks and subtasks' [9] in the training of functional daily living skills, advanced motor skills, and endurance [10]. It is based on the premise that the patient is a learner [11] who is guided through the practice of specific and relevant motor tasks in order to become effective and efficient in executing the learned motor tasks $[12,13]$. Successful implementation of TOET requires adherence to motor learning principles [11]. The TOET approach requires setting (i) a clear functional goal for the achievement of the desired activities of daily living $[14,15]$. The goal is set in collaboration with the patient and sometimes the patient's family $[15,16]$. It also requires (ii) active participation of the patient [9-11] in the accomplishment of functional and (iii) context-specific motor tasks [13-15] with 'real-world' object manipulation [15] - meaning that the child learns to use objects that are available in their homes (e.g. knife, hair brush, staircase, chairs, etc.) [15]. Further components of TOET include the use of (iv) context-specific training environment that reflects or mimics the natural environment for a specific task execution [15, 17, $18]$ and (v) random practice $[15,16,19,20]$. Nonetheless, a study found that block practice was superior to random practice in training people with $\mathrm{CP}$ [21]. The training schedule should involve (vi) either massed [19] or distributed practice $[14,15,22]$. The choice of training schedule may, however, depend on the goal of therapy and the individual's capabilities [20]. The training should advance towards (vii) practising the whole task [15, 19, 23], (viii) using a variety of exercises [9, $14,15]$, with (ix) positive reinforcement (feedback) [14, 15, 19]. Finally, the training should be $(x)$ individualized, with (xi) the load customized for each patient [14].

Studies have shown that TOET increased muscle strength [7, 24], functional balance [6, 8, 25, 26], participation [24], and self-care [27] among children with CP. Additionally, it improved mobility [27] by enhancing both standing and walking functions [5, 26, 28]. A study found, however, that TOET only improved standing ability and the gain recorded was not maintained in the follow-up period [24]. Another study implied that TOET did not improve lower limb function [29]. A systematic review revealed that TOET had strong evidence of improving upper extremity function and self-care in children with CP [30] but exhibited limited evidence of improving gross motor function [30, 31]. Strong recommendations have been made concerning the need for further research to determine the best ways to improve mobility function in these children [31, 32].

Despite the importance attached to the use of TOET components, many studies are unable to fully describe the specific components applied in their interventions. To date, only one study has used a customized training load for each patient [4]. Numerous studies have involved a limited number of training tasks [3, 4, 6, 33], therefore reducing the children's abilities to learn a variety of exercises related to accomplishing efficient

Correspondence address: Umaru Muhammad Badaru, Department of Physiotherapy, Faculty of Allied Health Sciences, Bayero University, P.M.B. 3011, Kano, Nigeria, e-mail: umbadaru.pth@buk.edu.ng 
movement function. Individualized training was not possible in group-based studies [7, 29]. Finally, many of the studies on TOET had no post-intervention follow-up [5, 8, 25, 26, 28], and thus it is difficult to know whether the gains in the variables trained were retained or not. The present study is designed to be more comprehensive with the use of customized training loads, as well as context-specific, block, whole-task, and distributed training schedules. A variety of exercises have been applied with a positive feedback and post-intervention follow-up [34].

In this study, mobility was operationally defined as the ability of children with CP to move from one postural position to another and from one location to another, and was assessed by using a mobility questionnaire. Walking efficiency was defined operationally as the ability of children with $\mathrm{CP}$ to cover a specific walking distance per a time unit. Functional performance in this study was evaluated by assessing the mobility and walking efficiency of children with CP. The study investigated the effects of TOET on the functional performance of children $\mathrm{CP}$.

\section{Subjects and methods}

\section{Study design}

The study was carried out in the Physiotherapy Departments of Aminu Kano Teaching Hospital in Kano and Murtala Mohammed Specialist Hospital in Kano, as well as in Usman International School, Kano. A total of 46 children were randomized into the TOET group $(n=23)$ and control group (CG) $(n=23)$. The flowchart of the study is presented in Figure 1. Included in this study were children with CP who could walk independently with or without walking aids. Excluded were children who had a severe musculoskeletal deformity in any of the lower limbs. Part of this research, the details of trial registration, ethical clearances, sample size determination, and the procedure for simple random sampling and blinding have been published recently [34]. All the children in the TOET group and CG were treated twice weekly for 12 weeks. There was a 6-week follow-up. Exercises in both groups were conducted for a total of 40 minutes per session.

\section{Treatment in the TOET group}

TOET involved practice of 6 exercises in 4 stations. Station 1 included forward step-up and unloaded sit-to-stand. Loaded sit-to-stand was practised in station 2. In station 3, high stick stepping and circular movement were practised. Station 4 involved staircase climbing and descending. A detailed description of the procedure of conducting each of the exercises was published previously [34]. A pretest repetition (PTR) was used to progress each of the exercises. The total number of repetitions of each exercise in 1 minute was the PTR [4].

\section{Exercise progression}

Forward step up, high stick-stepping, unloaded and loaded sit-to-stand exercises are progressed in the same manner. In the first 2 weeks of the training, each child performed 3 sets of $3 \times 50 \%$ of PTR. PTR was increased to $60 \%$ in the $3^{\text {rd }}$ and $4^{\text {th }}$ week, to $70 \%$ in the $5^{\text {th }}$ and $6^{\text {th }}$ week, to $80 \%$ in the $7^{\text {th }}$ and $8^{\text {th }}$ week, to $90 \%$ in the $9^{\text {th }}$ and $10^{\text {th }}$ week, and to $100 \%$ in the $11^{\text {th }}$ and $12^{\text {th }}$ week [34].

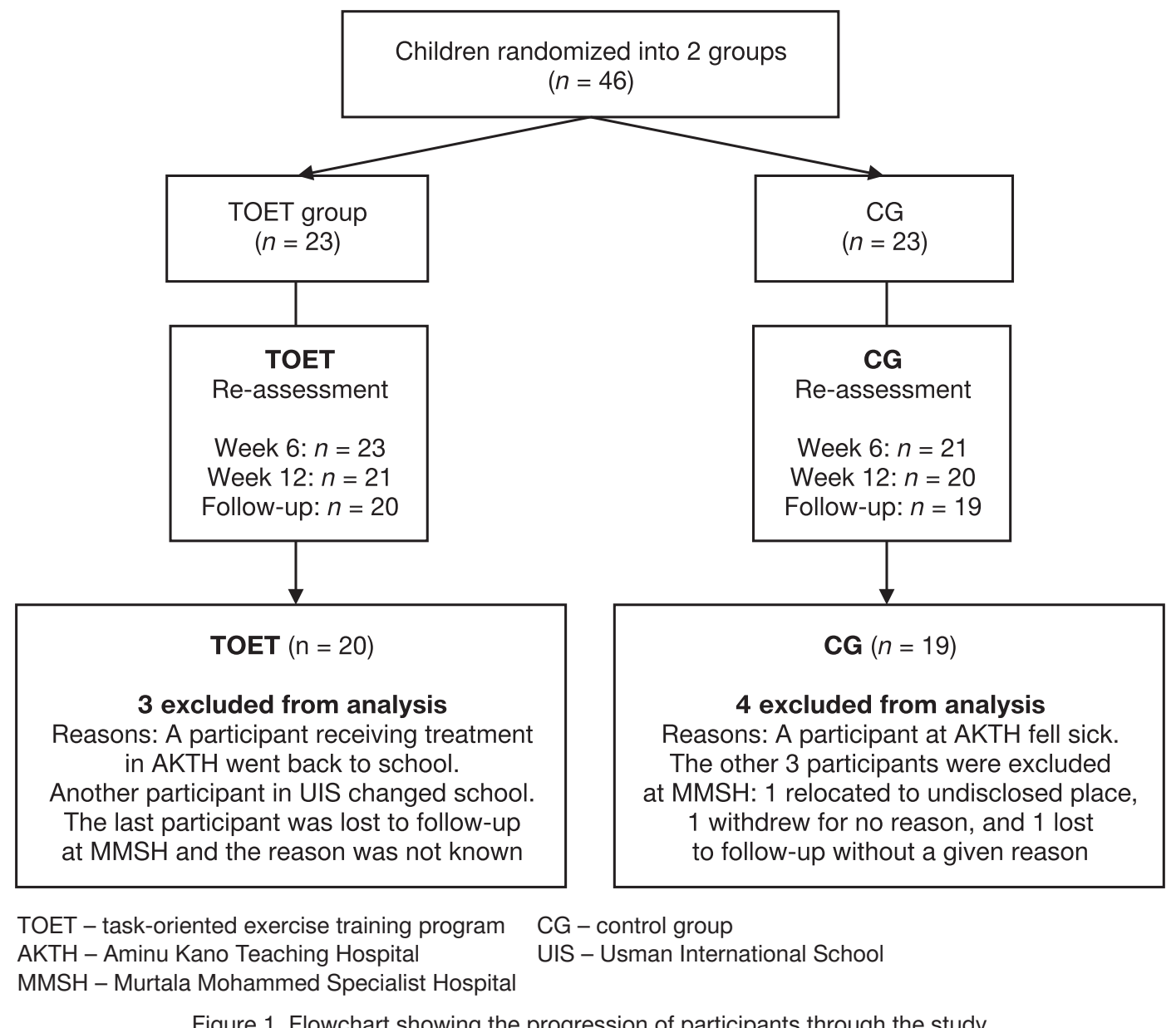


For example, in a child whose PTR for the unloaded sit-tostand was 10 repetitions per minute, 1 set of $3 \times 50 \%$ of PTR in first 2 weeks of training was $3 \times 0.5 \times 10=15$ repetitions (per set). Therefore, the child performed 3 sets of 15 repetitions of unloaded sit-to-stand per session during the first 2 weeks of training. Each exercise set for 1 minute was followed by 1 minute of rest.

\section{Exercise progression for circular movement and staircase climbing and descending}

Circular movement and staircase climbing and descending exercises are progressed in the same manner. This was done by adding 1 repetition of the exercise to PTR every 3 weeks. In the first 3 weeks of training, each of the children practised 3 sets of PTR plus 1 additional repetition of the exercise. There were additional 2 repetitions of the exercises in the $4^{\text {th }}-6^{\text {th }}$ weeks, 3 additional exercise repetitions in the $7^{\text {th }}-9^{\text {th }}$ weeks, and 4 additional repetitions in the $10^{\text {th }}-12^{\text {th }}$ weeks. For example, in a child whose PTR for circular movement was 5 repetitions per minute, 1 set of the exercise in the first 3 weeks of training was PTR $+1=5+1=6$ repetitions of circular movement. Therefore, the child performed 3 sets of 6 repetitions of circular movement per session during the first 3 weeks of training.

\section{Conventional physiotherapy for CG}

The conventional physiotherapy involved passive stretching, as well as active assisted, free active, and resisted exercises targeting lower limbs and trunk, which lasted for 40 minutes. A detailed description of the conventional physiotherapy program was published previously [34].

\section{Warm-up and cool-down sessions}

Each treatment session began with 5 minutes of warm-up exercise for both groups, which consisted of passive stretching of the calf muscles, hamstring, and hip adductors, followed by a 5-meter quick to-and-fro walk. Children in both groups had 5 minutes of cool-down at the end of each treatment session.

\section{Assessment of mobility}

Mobility was measured with a mobility questionnaire (MobQues 28). MobQues is both reliable and valid for measuring mobility limitations in children with $\mathrm{CP}$ as rated by the caregivers $[1,2,35]$. The instrument has high inter-rater reliability (intraclass correlation coefficient: 0.87 ) [1] and good content validity; the items were linked to the 'mobility' items of the International Classification of Functioning, Disability and Health with a moderate concurrent validity with the Gross Motor Function Measure-66 ( $r=0.67)$ [35]. Each of the 28 items of the questionnaire was scored on a 5-point scale ranging from 0 to 4 . The lowest score on the instrument was 0 and the highest score was 112 . The total scores were calculated by adding all item scores, dividing by the maximum possible score (i.e. 112), and multiplying by 100 . The total scores were expressed on a scale of 0-100 [1], with higher scores representing better mobility.

\section{Measurement of walking efficiency}

This was measured by using a 10-metre walk test. The in patients with neurological disabilities [36-38]. It has high test-retest (intraclass correlation coefficient: 0.81) [38] and intra-rater $(r=0.983)$ reliabilities in children with CP [38] and spinal cord injuries [29], respectively. It has concurrent validities of $r=0.67$ and $r=-0.71$ with the Berg Balance Scale and Emory Functional Ambulation Profile, respectively, in patients with stroke [36].

The test was performed with a 'flying start'. In the 'flying start,' the children were asked to walk a distance from 0 to 14 meters but only the time it took them to cover the distance between 2 and 12 meters at a self-selected walking speed was recorded. The timing started only when the child's leg crossed the 2-meter line and stopped when it crossed the 12-meter line. This helped to prevent errors in the measurement of walking speed that could be associated with an 'acceleration' at the beginning of the test and 'deceleration' at the end of the test. Walking efficiency was obtained as the waking speed by dividing the distance covered (i.e. 10 meters) by the total time (in seconds).

\section{Data analysis}

Repeated measures ANOVA was used to analyse within-group data on walking efficiency, measured at baseline, at $6^{\text {th }}$ and $12^{\text {th }}$ weeks of study, and after 6 weeks of follow-up. Friedman's test served to analyse within-group data on mobility, measured at baseline, at $6^{\text {th }}$ and $12^{\text {th }}$ weeks, and after 6 weeks of follow-up. Unpaired $t$-test was applied to compare between-group data on walking efficiency. The MannWhitney $U$ test allowed to compare between-group data on mobility. The analyses were conducted at the $\alpha$ level of $p \leq$ 0.05, with the SPSS software, version 20.

\section{Ethical approval}

The research related to human use has complied with all the relevant national regulations and institutional policies, has followed the tenets of the Declaration of Helsinki, and has been approved by the authors' institutional review board or an equivalent committee.

\section{Informed consent}

Informed consent has been obtained from the caregivers of all individuals included in this study after adequate explanation of the research procedure. The consent involved voluntariness, confidentiality, and non-maleficence, which were duly respected.

\section{Results}

A total of 39 children completed the study, 20 in the TOET group 19 in CG. There were 9 (45\%) males and 11 (55\%) females in the TOET group. CG comprised 9 (47.4\%) males and $10(52.6 \%)$ females. The mean age of the children was $8.7 \pm 3.0$ years (range: $4-12$ years) and $7.9 \pm 3.1$ years (range: 4-12 years) in the TOET group and CG, respectively. Seven participants dropped out, thus giving an attrition rate of $15.2 \%$. Half of the children in the TOET group (10; $50.0 \%)$ and most CG participants (12; 63.2\%) had the hemiplegic type of CP. In the TOET group, 7 (35\%) children had diplegic CP, 2 (10\%) had athetoid CP, and 1 (5\%) had ataxic CP. In CG, 4 (21.1\%) children had diplegic CP, 2 (10.5) had athetoid CP, and 1 (5.3\%) had monoparesis. The children in the TOET group presented gross motor function classification system scores of I $(7 ; 35 \%)$, II (6; 30\%), and III $(7 ; 35 \%)$, while the motor function scores in CG were I $(7 ; 36.85 \%)$, II $(7 ; 36.8 \%)$, and III $(5 ; 26.3 \%)$. The baseline scores for PTR 
were not significantly different between the groups $(p>0.05$ for all), as presented in Table 1. There was no significant correlation between $\mathrm{CP}$ type and scores for mobility at different time intervals in the TOET group $(r: 0.15-0.28 ; p>0.05$ for all). However, the type of CP showed a significant positive correlation with mobility scores at the $6^{\text {th }}$ week and $6^{\text {th }}$ week of follow-up in CG ( $r=0.5 ; p=0.03$ for all). The sex of children with $\mathrm{CP}$ had no significant correlation with scores for mobility at different time intervals in the TOET group $(r:-0.009$ to $0.06 ; p>0.05$ for all) or CG ( $r:-0.03$ to $0.27 ; p>0.05$ for all). Furthermore, type of CP showed no significant correlation with walking efficiency at different time intervals in the TOET group ( $r: 0.29-0.35 ; p>0.05$ for all) or CG ( $r: 0.34-0.41$; $p>0.05$ for all). There was no significant correlation between sex and scores for walking efficiency at different time intervals in the TOET group ( $r:-0.19$ to $0.03 ; p>0.05$ for all) or CG ( $r: 0.19-3.50 ; p>0.05$ for all).

Changes in scores for walking efficiency and mobility across study intervals

There were significant increases in mean scores of walking efficiency from baseline to the $6^{\text {th }}$ week of follow-up in both the TOET group $[\mathrm{F}(1.37,26.06)=122.57 ; p<0.0001]$ and CG $[F(1.63,29.40)=17.492 ; p<0.0001]$ (Table 2). The assumption of sphericity was violated, with Mauchly's test being significant in both the TOET group $\left(X^{2}=38.76\right.$; $d f=5$; $p<0.001)$ and CG $\left(X^{2}=36.63 ; d f=5 ; p<0.001\right)$. The Greenhouse-Geisser correction was used because of the value of $\varepsilon<0.75$ in both cases. The repeated measures ANOVA source table for walking efficiency is presented in Table 3 . The adjustment for multiple comparisons during post-hoc analyses was performed with the Bonferroni correction. Also, there were significant increases in the scores for mobility from baseline to the $6^{\text {th }}$ week of follow-up in both the the TOET group $\left(\chi^{2}=55.6 ; p=0.0001\right)$ and CG $\left(\chi^{2}=22.1 ; p=0.0001\right)$ (Table 4).

\section{Between-group comparison of mean scores} for walking efficiency at different time intervals

There were no significant differences in the scores for walking efficiency between the 2 groups at baseline $(t=-0.1$; $d f=37 ; p=0.94)$ or at the $6^{\text {th }}$ week $(t=-0.1 ; d f=37 ; p=0.92)$. Significant differences were observed in the scores for walking efficiency between the 2 groups at the $12^{\text {th }}$ week $(t=2.4$; $d f=37 ; p=0.02)$ and after 6 weeks of follow-up $(t=2.4 ; d f=37$; $p=0.02$ ) (Figure 2).

Table 1. Between-group comparison of scores for pretest repetitions at baseline

\begin{tabular}{|c|c|c|c|c|c|}
\hline Tasks & Group & Mean $\pm S D$ & $d f$ & $p$ & $95 \% \mathrm{Cl}$ \\
\hline \multirow{2}{*}{ Unloaded sit-to-stand } & TOET & $10.85 \pm 3.67$ & \multirow{2}{*}{37} & \multirow{2}{*}{0.76} & \multirow{2}{*}{-2.74 to 2.02} \\
\hline & $\mathrm{CG}$ & $11.21 \pm 3.66$ & & & \\
\hline \multirow{2}{*}{ Forward step-up } & TOET & $8.90 \pm 4.14$ & \multirow{2}{*}{37} & \multirow{2}{*}{0.90} & \multirow{2}{*}{-2.43 to $2.7 €$} \\
\hline & $\mathrm{CG}$ & $8.74 \pm 3.84$ & & & \\
\hline \multirow{2}{*}{ Loaded sit-to-stand } & TOET & $9.65 \pm 4.06$ & \multirow{2}{*}{37} & \multirow{2}{*}{0.99} & \multirow{2}{*}{-2.52 to 2.56} \\
\hline & CG & $9.63 \pm 3.756$ & & & \\
\hline \multirow{2}{*}{ High stick-stepping } & TOET & $8.00 \pm 4.39$ & \multirow{2}{*}{37} & \multirow{2}{*}{0.97} & \multirow{2}{*}{-2.72 to 2.6} \\
\hline & CG & $8.05 \pm 3.78$ & & & \\
\hline \multirow{2}{*}{ Circular movement } & TOET & $4.40 \pm 1.85$ & \multirow{2}{*}{37} & \multirow{2}{*}{0.88} & \multirow{2}{*}{-1.01 to 1.18} \\
\hline & CG & $4.32 \pm 1.49$ & & & \\
\hline \multirow{2}{*}{ Stair climbing and descending } & TOET & $3.05 \pm 1.28$ & \multirow{2}{*}{37} & \multirow{2}{*}{0.75} & \multirow{2}{*}{-0.55 to 0.76} \\
\hline & CG & $2.95 \pm 0.62$ & & & \\
\hline
\end{tabular}

SD - standard deviation, $d f$ - degrees of freedom, $\mathrm{Cl}$ - confidence interval,

TOET - task-oriented exercise training program, CG - control group

Table 2. Within-group changes in scores for walking efficiency across the study intervals in the TOET and control group $(n=39)$

\begin{tabular}{|c|c|c|c|c|c|c|c|c|}
\hline Groups & Variable & $\begin{array}{c}\text { Baseline } \\
(\text { mean } \pm S D)\end{array}$ & $\begin{array}{c}6^{\text {th }} \text { week } \\
(\text { mean } \pm S D)\end{array}$ & $\begin{array}{c}12^{\text {th }} \text { week } \\
(\text { mean } \pm S D)\end{array}$ & $\begin{array}{l}\text { Follow-up } \\
(\text { mean } \pm S D)\end{array}$ & $d f$ & $\mathrm{~F}$ & $p$ \\
\hline \multirow{2}{*}{ TOET } & \multirow{2}{*}{ Walking efficiency } & $0.6 \pm 0.2^{a}$ & $0.8 \pm 0.3^{b}$ & $1.00 \pm 0.3^{\mathrm{cd}}$ & $1.00 \pm 0.30^{d}$ & \multirow{2}{*}{1.37} & \multirow{2}{*}{122.6} & \multirow{2}{*}{$0.0001^{*}$} \\
\hline & & $(n=23)$ & $(n=23)$ & $(n=21)$ & $(n=20)$ & & & \\
\hline \multirow{2}{*}{ Control } & \multirow{2}{*}{ Walking efficiency } & $0.6 \pm 0.2^{\mathrm{a}}$ & $0.8 \pm 0.3^{b}$ & $0.8 \pm 0.3^{b}$ & $0.8 \pm 0.3^{b}$ & \multirow{2}{*}{1.63} & \multirow{2}{*}{17.49} & \multirow{2}{*}{$0.0001^{*}$} \\
\hline & & $(n=23)$ & $(n=21)$ & $(n=20)$ & $(n=19)$ & & & \\
\hline
\end{tabular}

Paired $t$-test post-hoc analysis: items with different superscripts (e.g. $X^{a}$ and $X^{b}$ ) are significantly different and items with at least one same superscript (e.g. $X^{c d}$ and $\left.X^{d}\right)$ are not significantly different. Adjustment for multiple comparisons was performed with the Bonferroni correction.

* significant

$d f$-degrees of freedom, TOET- task-oriented exercise training program, $n$ - sample size at a particular study period 
Table 3. Repeated measures ANOVA source table for walking efficiency

\begin{tabular}{|c|c|c|c|c|c|c|}
\hline \multicolumn{2}{|l|}{ Source } & $\begin{array}{l}\text { Type III sum } \\
\text { of squares }\end{array}$ & $d f$ & Mean square & $\mathrm{F}$ & $p$ \\
\hline \multicolumn{7}{|c|}{ Tests of within-subject effects (TOET group) } \\
\hline \multirow{4}{*}{ Factor 1} & Sphericity assumed & 2.08 & 3 & 0.70 & 122.57 & $0.0001^{*}$ \\
\hline & Greenhouse-Geisser & 2.08 & 1.37 & 1.52 & 122.57 & $0.0001^{*}$ \\
\hline & Huynh-Feldt & 2.08 & 1.44 & 1.45 & 122.57 & $0.0001^{*}$ \\
\hline & Lower-bound & 2.08 & 1.00 & 2.08 & 122.57 & $0.0001^{*}$ \\
\hline \multirow{4}{*}{ Error (factor 1) } & Sphericity assumed & 0.32 & 57 & 0.01 & & \\
\hline & Greenhouse-Geisser & 0.32 & 26.06 & 0.01 & & \\
\hline & Huynh-Feldt & 0.32 & 27.41 & 0.01 & & \\
\hline & Lower-bound & 0.32 & 19.00 & 0.02 & & \\
\hline \multicolumn{7}{|c|}{ Tests of within-subject contrasts (TOET group) } \\
\hline \multirow{3}{*}{ Factor 1} & Linear & 1.87 & 1 & 1.87 & 144.34 & $0.0001^{*}$ \\
\hline & Quadratic & 0.08 & 1 & 0.08 & 68.67 & $0.0001^{*}$ \\
\hline & Cubic & 0.14 & 1 & 0.14 & 47.46 & $0.0001^{*}$ \\
\hline \multirow{3}{*}{ Error (factor 1) } & Linear & 0.25 & 19 & 0.013 & & \\
\hline & Quadratic & 0.02 & 19 & 0.001 & & \\
\hline & Cubic & 0.06 & 19 & 0.003 & & \\
\hline \multicolumn{7}{|c|}{ Tests of between-subject effects (TOET group) } \\
\hline \multicolumn{2}{|l|}{ Intercept } & 57.40 & 1 & 57.40 & 208.56 & $0.0001^{*}$ \\
\hline \multicolumn{2}{|l|}{ Error } & 5.23 & 19 & 0.28 & & \\
\hline \multicolumn{7}{|c|}{ Tests of within-subject effects (control group) } \\
\hline \multirow{4}{*}{ Factor 1} & Sphericity assumed & 0.27 & 3 & 0.091 & 17.492 & $0.0001^{*}$ \\
\hline & Greenhouse-Geisser & 0.27 & 1.63 & 0.167 & 17.492 & $0.0001^{*}$ \\
\hline & Huynh-Feldt & 0.27 & 1.774 & 0.154 & 17.492 & $0.0001^{*}$ \\
\hline & Lower-bound & 0.27 & 1.000 & 0.272 & 17.492 & $0.001^{*}$ \\
\hline \multirow{4}{*}{ Error (factor 1) } & Sphericity assumed & 0.28 & 54 & 0.005 & & \\
\hline & Greenhouse-Geisser & 0.28 & 29.397 & 0.010 & & \\
\hline & Huynh-Feldt & 0.28 & 31.927 & 0.009 & & \\
\hline & Lower-bound & 0.28 & 18.000 & 0.016 & & \\
\hline \multicolumn{7}{|c|}{ Tests of within-subject contrasts (control group) } \\
\hline \multirow{3}{*}{ Factor 1} & Linear & 0.19 & 1 & 0.19 & 18.74 & $0.0001^{*}$ \\
\hline & Quadratic & 0.08 & 1 & 0.08 & 26.91 & $0.0001^{*}$ \\
\hline & Cubic & 0.01 & 1 & 0.01 & 3.23 & 0.09 \\
\hline \multirow{3}{*}{ Error (factor 1) } & Linear & 0.18 & 18 & 0.01 & & \\
\hline & Quadratic & 0.05 & 18 & 0.003 & & \\
\hline & Cubic & 0.05 & 18 & 0.003 & & \\
\hline \multicolumn{7}{|c|}{ Tests of between-subject effects (control group) } \\
\hline \multicolumn{2}{|l|}{ Intercept } & 41.40 & 1 & 41.40 & 170.16 & $0.0001^{*}$ \\
\hline \multicolumn{2}{|l|}{ Error } & 4.38 & 18 & 0.24 & & \\
\hline
\end{tabular}

* significant

TOET- task-oriented exercise training program, $d f$ - degrees of freedom; the Greenhouse-Geisser correction 
Table 4. Within-group changes in scores for mobility across the 4 periods in the TOET and control group $(n=39)$

\begin{tabular}{|c|c|c|c|c|c|c|c|}
\hline Groups & Variable & $\begin{array}{c}\text { Baseline } \\
(\text { mean } \pm S D)\end{array}$ & $\begin{array}{c}6^{\text {th }} \text { week } \\
(\text { mean } \pm S D)\end{array}$ & $\begin{array}{c}12^{\text {th }} \text { week } \\
(\text { mean } \pm S D)\end{array}$ & $\begin{array}{l}\text { Follow-up } \\
(\text { mean } \pm S D)\end{array}$ & $\chi^{2}$ & $p$ \\
\hline \multirow{2}{*}{ TOET } & \multirow{2}{*}{ Mobility } & $69.15 \pm 17.32^{a}$ & $75.54 \pm 12.85^{b}$ & $86.16 \pm 7.20^{\circ}$ & $86.70 \pm 6.86^{d}$ & \multirow{2}{*}{55.8} & \multirow{2}{*}{$0.0001^{*}$} \\
\hline & & $(n=23)$ & $(n=23)$ & $(n=21)$ & $(n=20)$ & & \\
\hline \multirow{2}{*}{ Control } & \multirow{2}{*}{ Mobility } & $67.03 \pm 10.49^{a}$ & $69.0 \pm 12.70^{b}$ & $71.09 \pm 13.58^{c}$ & $67.47 \pm 11.76^{\mathrm{ab}}$ & \multirow{2}{*}{22.12} & \multirow{2}{*}{$0.0001^{*}$} \\
\hline & & $(n=23)$ & $(n=21)$ & $(n=20)$ & $(n=19)$ & & \\
\hline
\end{tabular}

Wilcoxon signed rank post-hoc analysis: items with different superscripts (e.g. $\chi^{\mathrm{a}}$ and $\chi^{\mathrm{b}}$ ) are significantly different and items with at least one same superscript (e.g. $\chi^{\text {ab }}$ and $\chi^{\mathrm{a}}$ ) are not significantly different.

${ }^{*}$ significant

TOET- task-oriented exercise training program, $n$ - sample size at a particular study period

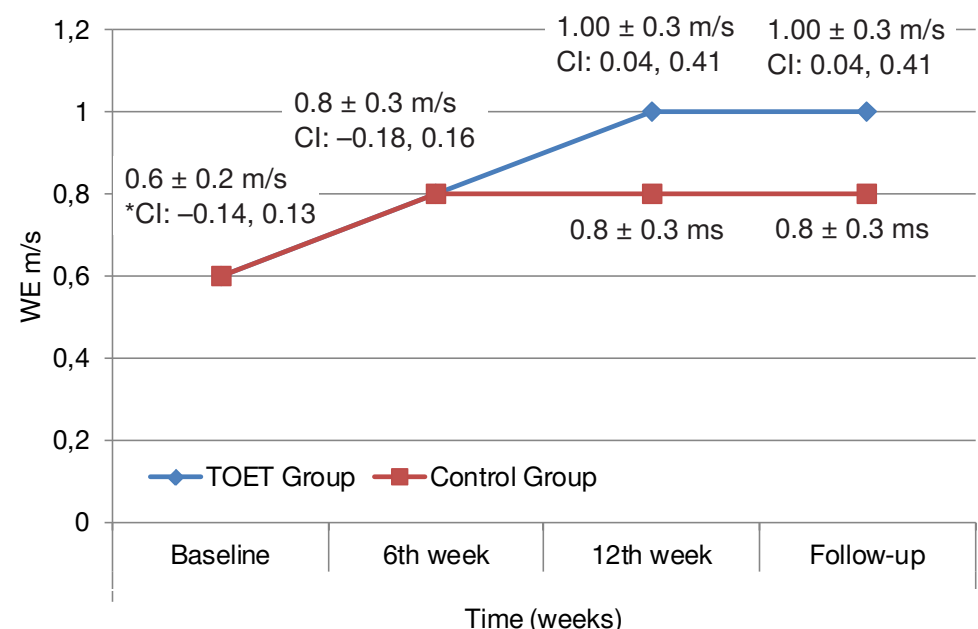

Time (weeks)
WE - walking efficiency

$\mathrm{Cl}-95 \%$ confidence interval

TOET - task-oriented exercise training program

${ }^{*} \mathrm{Cl}$ of the mean between-group difference

Figure 2. Between-group comparison of mean scores for walking efficiency

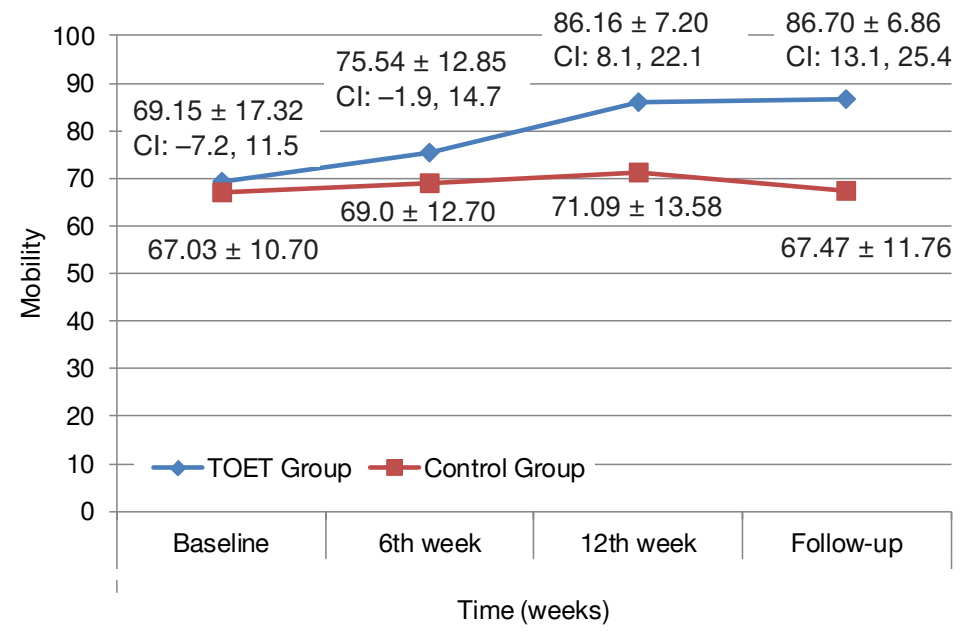

$\mathrm{Cl}-95 \%$ confidence interval of the mean betweengroup difference

TOET - task-oriented exercise training program

Figure 3. Between-group comparison of mean scores for mobility
Between-group comparison of mean scores for mobility at different time intervals

Also, there was no significant difference in the scores for mobility between the 2 groups at baseline $(Z=-0.7 ; p=0.52)$ or at the $6^{\text {th }}$ week $(Z=-1.8 ; p=0.07)$. Significant betweengroup differences were, however, recorded in mobility scores at the $12^{\text {th }}$ week $(Z=-3.5 ; p=0.0001)$ and after 6 weeks of follow-up $(Z=-4.4 ; p=0.0001)$ (Figure 3$)$.

\section{Discussion}

In this study, the significant change that occurred in the scores for walking efficiency after 12 weeks of training implies that TOET led to an improvement in the functional performance of children with $\mathrm{CP}$, especially with regard to the significant increase in the walking speed. The non-significant difference in the scores for walking efficiency after 6 weeks of follow-up subsequent to the 12-week training indicates that the gain recorded in walking efficiency after the practice of TOET was retained after training cessation. This result is similar to the outcome of a study in which intensive TOET 
significantly improved walking efficiency and the gain was retained after training cessation [7]. Another study also revealed that an intensive regimen of TOET increased walking efficiency in children with a diplegic type of CP [8]. It was, however, observed that walking efficiency was not significantly improved after the practice of home-based TOET [4]. Though the home-based TOET involved a customized training load for each patient, the study did not adequately explain how the other components of TOET were utilized for the training.

The possible reason for the similarity in the outcome of walking efficiency in this study and those by Blundell et al. [7] and Kumar and Ostwal [8] could be that those researchers also used a variety of TOET exercises to train movement function, whereas the home-based TOET [4] utilized only the sit-to-stand and step-up exercise for lower limb training. This exercise lacked variety and could therefore have limited the ability of children with CP to improve their walking efficiency.

The significant change that was observed in the scores for walking efficiency in CG implies that routine physiotherapy exercises resulted in a significant improvement in walking efficiency as the participants were able to cover a distance of 10 metres in a significantly shorter time. However, the observation that a significant change occurred in the score of walking efficiency between baseline and the $6^{\text {th }}$ week, in contrast to any other time point in the study, means that conventional exercises produced a significant improvement in walking efficiency mostly within the first 6 weeks of training, with a negligible improvement afterwards. The possible implication of this finding is that the greatest gain in walking efficiency that may be observed with the practice of routine physiotherapy exercise may occur within the first few weeks of training, after which there may be very little change in walking efficiency with continued training.

The finding in this study that there was a significant between-group difference in the scores for walking efficiency only at the $12^{\text {th }}$ week and at the end of the follow-up period in favour of the TOET group means that children who received TOET presented a significantly better improvement in their scores for walking efficiency than those who practised conventional physiotherapy exercises, but only when the training was conducted beyond 6 weeks. The implication of this finding is that TOET will produce a better improvement in the walking efficiency of children with $\mathrm{CP}$ than the practice of conventional exercise only when the training is conducted beyond 6 weeks. The possible reason for the significant improvement that was observed in walking efficiency among children who practised TOET when compared with those who did conventional exercises could be that in the TOET group, the training load was customized and context-specific, with active participation and active problem solving, which was not the case with the conventional exercise group. The outcome of this study on walking efficiency was, however, different from the findings of other studies $[3,8]$. Contrary to the outcome of this study, Liao et al. [3] reported that 18 sessions of added home-based loaded sit-to-stand exercise did not produce a significant improvement in walking efficiency compared with regular physiotherapy only. The possible reason for the difference in outcome between this study and that in which home-based loaded sit-to-stand exercise was practised [3] could be that practising sit-to-stand exercises alone may not be 'context-specific' with regard to the training of walking function because it could limit the children's abilities to learn a variety of functional task-related exercises associated with movement function, such as walking, climbing, running, etc. Furthermore, another differing result was obtained in a study in which intensive regimen of TOET was not significantly better than proprioceptive neuromuscular facilitation for improving walking efficiency [8]. This result may have been influenced by fatigue because 24 training sessions in 4 weeks could be very tasking for children with CP. This is probably one of the reasons why studies recommended distributed practice schedules that are less intensive [14, $15,22]$.

The results obtained in this study show that the scores for mobility increased significantly with training among children in the TOET group. This implies that TOET resulted in an increased ability of children with CP to move from one postural position to another and from one location to another. This improvement recorded during the training was retained 6 weeks after the training discontinuation. The outcome is probably due to the fact that TOET provides sufficient opportunities to children with $\mathrm{CP}$ to practise activities integrated with the everyday environment [39]. This finding is in line with previous research results where TOET involving circling, random movement, and weight-shifting tasks among children with congenital hemiplegia led to a significant improvement in the trained task and in the symmetry of gait patterns [40]. It was similarly reported that TOET was used to improve mobility function [6] and balance [6, 25] in children with CP. Furthermore, another study revealed that an 8-week task-oriented training that was focused on strengthening the lower extremities led to a significant improvement in the mobility function and postural stability of children with CP [41]. On the contrary, Crompton et al. [29] found that group-based lower-limb TOET did not produce a significant improvement in the walking distance after the intervention or at follow-up, probably because the group-based training did not use a customized training load for each participant, hence the subjects may not have achieved the individualized training goals.

The participants in CG experienced a significant improvement in their scores for the mobility function after the practice of conventional exercise training. However, a significant reduction in mobility scores was observed when the training was discontinued for 6 weeks, which means that the gain recorded in the mobility function after conventional exercises was not retained after training cessation. The possible interpretation of this finding is that it may be very challenging for children who undergo conventional exercises to retain the improvement in mobility when the programme is stopped. This would therefore require continuous practice of routine physiotherapy exercises to maintain the mobility function in children with $\mathrm{CP}$.

It was observed in this study that children who practised TOET showed a more significant improvement in their mobility scores than those who practised conventional exercise. The negligible between-group difference in scores of mobility at the $6^{\text {th }}$ week, which was significant afterwards, implies that TOET may lead to a better improvement in mobility than conventional exercise when training is conducted beyond 6 weeks. This outcome is similar to the findings that children in the TOET group recorded a significant improvement in the gait and balance functions compared with those in the conventional therapy group [28].

\section{Limitations}

Block practice was utilized for the training instead of the recommended random practice because it is very difficult to implement random practice during lower limb TOET, unlike in the case of the upper limb. This is therefore a limitation of this study. 


\section{Conclusions}

TOET is an effective intervention for the improvement of functional performance in children with CP. TOET training produced sustained improvement of functional performance and is more effective than conventional exercise.

\section{Disclosure statement}

Dr U.M. Badaru received financial support from TETFund for degree awarding research.

\section{Conflict of interest}

The authors state no conflict of interest.

\section{References}

1. Van Ravesteyn NT, Dallmeijer AJ, Scholtes VA, Roorda LD, Becher JG. Measuring mobility limitations in children with cerebral palsy: interrater and intrarater reliability of a mobility questionnaire (MobQues). Dev Med Child Neurol. 2010;52(2):194-199; doi: 10.1111/j.1469-8749.2009. 03341.x.

2. Roorda LD, Scholtes VA, van der Lee JH, Becher J, Dallmeijer AJ. Measuring mobility limitations in children with cerebral palsy: development, scalability, unidimensionality, and internal consistency of the Mobility Questionnaire, MobQues47. Arch Phys Med Rehabil. 2010;91(8): 1194-1209; doi: 10.1016/j.apmr.2010.05.009.

3. Liao H-F, Liu Y-C, Liu W-Y, Lin Y-T. Effectiveness of loaded sit-to-stand resistance exercise for children with mild spastic diplegia: a randomized clinical trial. Arch Phys Med Rehabil. 2007;88(1):25-31; doi: 10.1016/j.apmr.2006. 10.006 .

4. Katz-Leurer M, Rotem H, Keren O, Meyer S. The effects of a 'home-based' task-oriented exercise programme on motor and balance performance in children with spastic cerebral palsy and severe traumatic brain injury. Clin Rehabil.2009;23(8):714-724;doi:10.1177/0269215509 335293.

5. Salem Y, Godwin EM. Effects of task-oriented training on mobility function in children with cerebral palsy. NeuroRehabilitation. 2009;24(4):307-313; doi: 10.3233/ NRE-2009-0483.

6. Kumban W, Amatachaya S, Peungsuwan P, Siritaratiwat W. Effects of sit to stand training on functional balance of children with cerebral palsy [in Thai]. J Med Tech Phy Ther. 2010;22(3):280-291.

7. Blundell SW, Shepherd RB, Dean CM, Adams RD, Cahill BM. Functional strength training in cerebral palsy: a pilot study of a group circuit training class for children aged 4-8 years. Clin Rehabil. 2003;17(1):48-57; doi: 10.1191/0269215503cr584oa.

8. Kumar C, Ostwal P. Comparison between task-oriented training and proprioceptive neuromuscular facilitation exercises on lower extremity function in cerebral palsy a randomized clinical trial. J Nov Physiother. 2016;6(3): 291; doi: 10.4172/2165-7025.1000291.

9. Nadeau S, Duclos C, Bouyer L, Richards CL. Guiding task-oriented gait training after stroke or spinal cord injury by means of a biomechanical gait analysis. Prog Brain Res. 2011;192:161-180; doi: 10.1016/B978-0444-53355-5.00011-7.

10. Shumway-Cook A, Woollacott MH. A conceptual framework for clinical practice. In: Shumway-Cook A, Woollacott $\mathrm{MH}$, Motor control. Translating research into clinical practice. Philadelphia: Lippincott Williams \& Wilkins; 2007; 136-153.
11. Carr JH, Shepherd RB. A motor learning model for stroke rehabilitation. Physiotherapy. 1989;75(7):372-380; doi: 10.1016/S0031-9406(10)62588-6.

12. Bayona NA, Bitensky J, Salter K, Teasell R. The role of task-specific training in rehabilitation therapies. Top Stroke Rehabil. 2005;12(3):58-65; doi: 10.1310/BQM56YGB-MVJ5-WVCR.

13. Carr JH, Shepherd RB. The changing face of neurological rehabilitation. Rev Bras Fisioter. 2006;10(2):147156; doi: 10.1590/S1413-35552006000200003.

14. Timmermans AAA, Spooren AIF, Kingma H, Seelen HAM. Influence of task-oriented training content on skilled armhand performance in stroke: a systematic review. Neurorehabil Neural Repair. 2010;24(9):858-870; doi: 10.1177/ 1545968310368963.

15. Ward N. Treatment of arm and hand dysfunction after CNS damage. In: Dietz V, Ward N (eds.), Oxford textbook of neurorehabilitation. Oxford: Oxford University Press; 2015; 238-250.

16. Larin HM. Motor learning: a practical framework for paediatric physiotherapy. Physiother Theory Pract. 1998; 14(1):33-47; doi: 10.3109/09593989809070042.

17. Ma HI, Trombly CA, Robinson-Podolski C. The effect of context on skill acquisition and transfer. Am J Occup Ther. 1999;53(2):138-144; doi: 10.5014/ajot.53.2.138.

18. Kenyon LK, Blackinton MT. Applying motor-control theory to physical therapy practice: a case report. Physiother Can. 2011;63(3):345-354; doi: 10.3138/ptc.2010-06.

19. Hubbard IJ, Parsons MW, Neilson C, Carey LM. Taskspecific training: evidence for and translation to clinical practice. Occup Ther Int. 2009;16(3-4):175-189; doi: 10.1002/oti.275.

20. Muratori LM, Lamberg EM, Quinn L, Duff SV. Applying principles of motor learning and control to upper extremity rehabilitation. J Hand Ther. 2013;26(2):94-103; doi: 10.1016/j.jht.2012.12.007.

21. Morriss L, Wittmannová J. The effect of blocked versus random training schedules on boccia skills performance in experienced athletes with cerebral palsy. Eur J Adapt Phys Act. 2010;3(2):17-28; doi: 10.5507/euj.2010.006.

22. Magill RA. The amount and distribution of practice. In: Magill RA (ed.), Motor learning and control: concepts and applications. Boston: McGraw-Hill; 2007; 390-404.

23. Zwicker JG, Harris SR. A reflection on motor learning theory in pediatric occupational therapy practice. Can J Occup Ther. 2009;76(1):29-37; doi: 10.1177/0008417 40907600108.

24. Verschuren O, Ketelaar M, Gorter JW, Helders PJM, Uiterwaal CSPM, Takken T. Exercise training program in children and adolescents with cerebral palsy: a randomized controlled trial. Arch Pediatr Adolesc Med. 2007; 161(11):1075-1081; doi: 10.1001/archpedi.161.11.1075.

25. Kim Y, Lee B-H. Clinical usefulness of child-centered taskoriented training on balance ability in cerebral palsy. $J$ Phys Ther Sci. 2013;25(8):947-951; doi: 10.1589/jpts. 25.947.

26. Kumar C, Kataria S. Effectiveness of task oriented circuit training on functional mobility and balance in cerebral palsy. Indian J Physiother Occup Ther. 2013;7(4): 23-28; doi: 10.5958/j.0973-5674.7.4.116.

27. Ketelaar M, Vermeer A, Hart H, van Petegem-van Beek E, Helders PJ. Effects of a functional therapy program on motor abilities of children with cerebral palsy. Phys Ther. 2001;81(9):1534-1545; doi: 10.1093/ptj/81.9.1534.

28. Han $\mathrm{H}-\mathrm{K}$, Chung $\mathrm{Y}$. Effects of task-oriented training for gross motor function measure, balance and gait func- 
tion in persons with cerebral palsy. Phys Ther Rehabil Sci. 2016;5(1):9-14; doi: 10.14474/ptrs.2016.5.1.9.

29. Crompton J, Imms C, McCoy AT, Randall M, Eldridge B, Scoullar B, et al. Group-based task-related training for children with cerebral palsy: a pilot study. Phys Occup Ther Pediatr. 2007;27(4):43-65; doi: 10.1080/J006v27 n04_04.

30. Novak I, Mclntyre S, Morgan C, Campbell L, Dark L, Morton N, et al. A systematic review of interventions for children with cerebral palsy: state of the evidence. Dev Med Child Neurol. 2013;55(10):885-910; doi: 10.1111/ dmcn.12246.

31. Toovey R, Bernie C, Harvey AR, McGinley JL, Spittle AJ. Task-specific gross motor skills training for ambulant school-aged children with cerebral palsy: a systematic review. BMJ Paediatr Open. 2017;1:e000078; doi: 10.1136/bmjpo-2017-000078.

32. Das SP, Ganesh GS. Evidence-based approach to physical therapy in cerebral palsy. Indian J Orthop. 2019;53(1): 20-34; doi: 10.4103/ortho.IJOrtho_241_17.

33. Kumban W, Amatachaya S, Emasithi A, Siritaratiwat W. Effects of task-specific training on functional ability in children with mild to moderate cerebral palsy. Dev Neurorehabil. 2013;16(6):410-417; doi: 10.3109/17518423. 2013.772672.

34. Ogwumike OO, Badaru UM, Adeniyi AF. Effect of taskoriented training on balance and motor function of ambulant children with cerebral palsy. Rehabilitacion. 2019; 53(4):276-283; doi: 10.1016/j.rh.2019.07.003.

35. Van Ravesteyn NT, Scholtes VA, Becher JG, Roorda LD, Verschuren O, Dallmeijer AJ. Measuring mobility limitations in children with cerebral palsy: content and construct validity of a mobility questionnaire (MobQues). Dev Med Child Neurol. 2010;52(10):229-235; doi: 10.1111/ j.1469-8749.2010.03729.x.

36. Wolf SL, Catlin PA, Gage K, Gurucharri K, Robertson R, Stephen K. Establishing the reliability and validity of measurements of walking time using the Emory Functional Ambulation Profile. Phys Ther. 1999;79(12):1122-1133; doi: 10.1093/ptj/79.12.1122.

37. Van Hedel HJ, Wirz M, Dietz V. Assessing walking ability in subjects with spinal cord injury: validity and reliability of 3 walking tests. Arch Phys Med Rehabil. 2005;86(2): 190-196; doi: 10.1016/j.apmr.2004.02.010.

38. Thompson P, Beath T, Bell J, Jacobson G, Phair T, Salbach NM, et al. Test-retest reliability of the 10-metre fast walk test and 6-minute walk test in ambulatory schoolaged children with cerebral palsy. Dev Med Child Neurol. 2008;50(5):370-376; doi:10.1111/j.1469-8749.2008. 02048.x.

39. Choi $\mathrm{Y}$, Jung $\mathrm{H}$. A commentary on task-oriented interventions in the functional mobility and postural control of children with cerebral palsy. Int J Neurorehabilitation. 2018;5(2):314; doi: 10.4172/2376-0281.1000314.

40. Ledebt A, Becher J, Kapper J, Rozendaal RM, Bakker R, Leenders IC, et al. Balance training with visual feedback in children with hemiplegic cerebral palsy: effect on stance and gait. Motor Control. 2005;9(4):459-468; doi: 10.1123/mcj.9.4.459.

41. Kim J-H, Choi Y-E. The effect of task-oriented training on mobility function, postural stability in children with cerebral palsy. J Korean Soc Phys Med. 2017;12(3):7984; doi: 10.13066/kspm.2017.12.3.79. 